\title{
Damping Augmentation of Nanocomposites Using Carbon Nanofiber Paper
}

\author{
Jihua Gou, ${ }^{1}$ Scott $O^{\prime}$ Braint, ${ }^{1}$ Haichang Gu, ${ }^{2}$ and Gangbing Song ${ }^{2}$ \\ ${ }^{1}$ Department of Mechanical Engineering, University of South Alabama, Mobile, AL 36688-0002, USA \\ ${ }^{2}$ Department of Mechanical Engineering, University of Houston, Houston, TX 77204-4006, USA
}

Received 11 January 2006; Accepted 4 May 2006

Vacuum-assisted resin transfer molding (VARTM) process was used to fabricate the nanocomposites through integrating carbon nanofiber paper into traditional glass fiber reinforced composites. The carbon nanofiber paper had a porous structure with highly entangled carbon nanofibers and short glass fibers. In this study, the carbon nanofiber paper was employed as an interlayer and surface layer of composite laminates to enhance the damping properties. Experiments conducted using the nanocomposite beam indicated up to $200-700 \%$ increase of the damping ratios at higher frequencies. The scanning electron microscopy (SEM) characterization of the carbon nanofiber paper and the nanocomposites was also conducted to investigate the impregnation of carbon nanofiber paper by the resin during the VARTM process and the mechanics of damping augmentation. The study showed a complete penetration of the resin through the carbon nanofiber paper. The connectivities between carbon nanofibers and short glass fibers within the carbon nanofiber paper were responsible for the significant energy dissipation in the nanocomposites during the damping tests.

Copyright (c) 2006 Jihua Gou et al. This is an open access article distributed under the Creative Commons Attribution License, which permits unrestricted use, distribution, and reproduction in any medium, provided the original work is properly cited.

\section{INTRODUCTION}

In recent years, nanoparticles have been attracting increasing attention in the composite community as they are capable of improving the mechanical and physical properties of traditional fiber reinforced composites [1-4]. Their nanometer size, leading to high specific surface areas of up to more than $1000 \mathrm{~m}^{2} / \mathrm{g}$ and extraordinary mechanical, electrical, and thermal properties make them unique nano-fillers for structural and multifunctional composites. Commonly used nanoparticles in nanocomposites include multiwalled nanotubes (MWNTs), single-walled nanotubes (SWNTs), carbon nanofibers (CNFs), montmorillonite (MMT) nanoclays, and polyhedral oligomeric silsesquioxanes (POSS). Other nanoparticles, such as $\mathrm{SiO}_{2}, \mathrm{Al}_{2} \mathrm{O}_{3}, \mathrm{TiO}_{2}$, and nanosilica are also used in the nanocomposites. Compared to other particulate additives, carbon nanotubes and carbon nanofibers offer more advantages. The addition of small size and low loading of carbon nanotubes and carbon nanofibers can enhance the matrix-dominated properties of composites, such as stiffness, fracture toughness, and interlaminar shear strength [5-9]. They have proven to be excellent additives to impart electrical conductivity in nanocomposites at lower loadings due to their high electrical conductivity and aspect ratio [10-12]. In addition, they have better performance as flame retardant by reducing the heat release rate of polymer and conducting heat away from the flame zone $[13,14]$.

While there are many reported benefits of carbon nanotubes and carbon nanofibers in composites, the potential of carbon nanotubes and carbon nanofibers to enhance the damping properties of composites has been less explored. Traditional damping enhancements of composites are based on viscoelastic polymer materials [15], carbon fiber prepregs [16], and magnetostrictive particles [17]. The major limitations of the viscoelastic polymer materials are the structural integrity issue, the sacrifice of stiffness and strength of the composite system due to the resin penetration, and poor thermal stability. Kishi et al. [16] evaluated the damping properties of composite laminates with/without the interleaved films. The effects of the lay-up arrangements of carbon fiber prepregs on the damping properties of the interleaved laminates were examined. The viscoelastic properties of interleaved polymer films were reflected in the damping properties of the corresponding interleaved laminates. Magnetostrictive particles have been used in a polymer matrix as active transducer and passive damper, providing stiffness and strength while incorporating damping capabilities. Pulliam et al. [17] developed a novel manufacturing technique based on magnetic fields to distribute magnetostrictive 
particles in polymer resins and applied them in thin-layer on the surfaces for vibration damping. Recently, carbon nanotubes have been used in the composite system for structural damping and stiffness augmentation. Suhr et al. [18] conducted direct shear testing of epoxy thin films containing multiwalled carbon nanotubes and reported strong viscoelastic behavior with up to $1400 \%$ increase in loss factor (damping ratio) of the baseline epoxy resin. The great improvement in damping was achieved without sacrificing the mechanical strength and stiffness of the polymer, and with minimal weight penalty. Koratkar et al. [19, 20] fabricated multiwalled nanotube thin films by using catalytic chemical vapor deposition of xylene-ferrocene mixture precursor. The nanotube films were employed as interlayers to reinforce the interfaces between composite plies, enhancing laminate stiffness and structural damping. The flatwise bending tests of a piezosilica composite beam with an embedded nano-film sublayer indicated up to $200 \%$ increase in the damping level and 30\% increase in the baseline bending stiffness.

Traditionally, researchers fabricated composites by directly mixing carbon nanotubes and carbon nanofibers into polymers and then using casting and injection techniques to make nanocomposites. Gou et al. [21, 22] have developed a new technique approach to fabricate nanocomposites using single-walled carbon nanotube bucky papers. The experimental details of fabrication of single-walled carbon nanotube bucky paper can be found in reference [23]. The dynamic mechanical analysis (DMA) results indicated an enhancement of the thermomechanical properties of single-walled carbon nanotube bucky paper/epoxy resin nanocomposites. The present work describes the integration of carbon nanofiber paper as damping material into large structural level laminates-glass fiber reinforced composites. The very first time an example of carbon nanofiber paper-enabled nanocomposites in the dimension of a structural element is presented. The manufacturing via VARTM and the investigation of the damping properties and tensile properties of the fabricated nanocomposites are described.

\section{EXPERIMENTAL DETAILS}

\subsection{Materials}

The carbon nanofiber paper used in this study was obtained from Applied Sciences, Inc. The carbon nanofiber paper had good strength and flexibility to allow for handling like traditional glass fiber mat. The carbon nanofiber paper was composed of short glass fibers and vapor grown carbon nanofibers (Polygraf III) with diameter of 100-150 nm and length of $30-100 \mu \mathrm{m}$. The short glass fiber and carbon nanofibers appeared in an entangled and porous form within the paper. The unsaturated polyester resin (product code: 712-6117, Eastman Chemical Company) was used as matrix material for glass fiber reinforced composites. The polyester resin was used with the MEK peroxide hardener at a weight ratio of $100: 1$.

\subsection{Manufacturing of carbon nanofiber paper-enabled nanocomposites}

The VARTM process has been widely used to produce lowcost, high-quality, and geometrically complicated composite parts. In this study, the VARTM process was used to fabricate the carbon nanofiber paper-enabled nanocomposites, which was carried out in three steps. In the first step, glass fiber mats carbon nanofiber paper were placed on the bottom half of a mold. After the lay-up operation was completed, a peel ply, resin distribution media, and vacuum bag film were placed on the top of fiber mats. The vacuum film bag was then sealed around the perimeter of the mold and a vacuum pump was used to draw a vacuum within the mold cavity. The next step was the mold filling during which resin was sucked into the mold under atmospheric pressure. In the VARTM process, the distribution media provided a high permeability region in the mold cavity, which allowed the resin to quickly flow across the surface of the laminate and then wet the thickness of the laminate. Therefore, the dominant impregnation mechanism in the VARTM process was the through-thickness flow of resin. In the final step, the composite part was cured at room temperature for 24 hours and post-cured in the oven for another 2 hours at $100^{\circ} \mathrm{C}$.

In this study, the test laminates consisted of six plies of fiberglass with a single layer of carbon nanofiber paper embedded at the surface or the midplane. In the manufacturing of composite laminates with carbon nanofiber as an interlayer, one layer of carbon nanofiber paper was placed between the fiber mats. The peel ply and resin distribution media were used on both top and bottom sides to facilitate the resin flow through the thickness.

\subsection{Damping test of carbon nanofiber paper-enabled nanocomposites}

The regular composite beam without carbon nanofiber paper and the nanocomposite beam with carbon nanofiber paper were used as the specimens for damping test. For each beam, a PZT (lead zirconate titanate, a type of piezoceramic material $)$ patch $(20 \mathrm{~mm} \times 20 \mathrm{~mm})$ was attached on one side as an actuator to excite the beam and a smaller PZT patch $(10 \mathrm{~mm} \times 8 \mathrm{~mm})$ was attached on the other side of the beam as a sensor to detect the beam's vibration, as shown in Figure 1. A micro laser sensor (NAIS-LM10-ANR12151) was also used to detect the beam's tip displacement. The micro laser sensor had a resolution of $20 \mu \mathrm{m}(0.0008 \mathrm{inch})$. The testing specimen was clamped on an aluminum stand as shown in Figure 2.

\subsection{Tensile test of carbon nanofiber paper-enabled nanocomposites}

The tensile tests were performed using the VARTM manufactured composite laminates with and without carbon nanofiber paper. The tensile tests on the composite beams were conducted according to ASTM test standards. All these tests were performed on a Qualitest testing machine. 


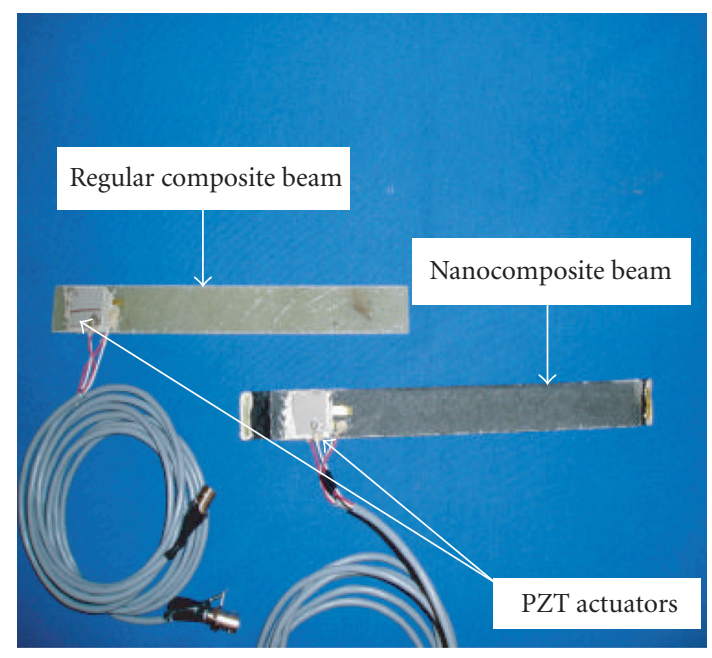

FIGURE 1: Regular composite beam and nanocomposite beam for damping test.

\subsection{Electron microscopy}

The SEM images were taken to study the porous structure of carbon nanofiber paper and the impregnation of carbon nanofiber paper by the resin. The interface between the carbon nanofiber paper and the resin was examined. The SEM specimens of the nanocomposites were obtained by the ultra microtome cutting.

\section{RESULTS AND DISCUSSION}

\subsection{SEM observations of carbon nanofiber paper and nanocomposites}

Figure 3(a) shows the carbon nanofiber paper used in this research, which can be handled like traditional glass fiber mats. The SEM images of carbon nanofiber paper are shown in Figures 3(b) and 3(c). These images show the multiscale porous structure of carbon nanofiber paper formed by short glass fibers and carbon nanofibers. The pore size formed by short glass fibers was in the range of $100-200 \mu \mathrm{m}$ and the pores formed by carbon nanofibers had an average opening around $1 \mu \mathrm{m}$. The carbon nanofibers within the paper have an average diameter about $100-150 \mathrm{~nm}$. Figure 3(d) shows the SEM image of the fracture surface of the nanocomposites embedded with carbon nanofiber paper. This sample was fractured under tensile force. It can be clearly seen that the resin had completely penetrated the carbon nanofiber paper through the thickness direction during the VARTM process.

\subsection{Damping properties of carbon nanofiber-enabled composite laminates}

The damping test was conducted on the composite laminates with carbon nanofiber paper as midlayer and surface layer. During the damping test, the sweep sinusoidal signals were used as excitation source for the PZT actuator to get

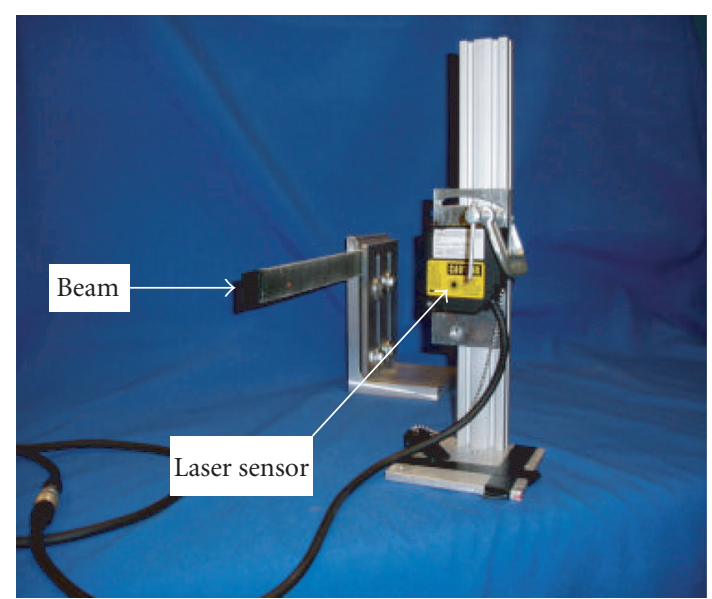

FIgURE 2: Experimental setup for damping test.

the frequency response of the system. Two different sweep sine signals were used for the test. One sweep sine was from $0.1 \mathrm{~Hz}$ to $100 \mathrm{~Hz}$ to get detailed information about the first mode frequency. The other sweep sine was from $10 \mathrm{~Hz}$ to $1000 \mathrm{~Hz}$ to excite the first few modes. The sweeping period of both sweep sines was set as 20 seconds. The sampling frequency was set as $40 \mathrm{kHz}$. For the nanocomposite beam with carbon nanofiber paper as midlayer, the time responses of both sweep sine excitations are shown in Figures 4 and 5, respectively. The peak value in the sweep sine response represents resonance at a certain natural frequency. From the sweep sine responses, it can be clearly seen that the peaks of first mode, second mode, and third mode are significantly reduced for the nanocomposite beam, which indicates that the nanocomposite beam has improved damping property.

To further demonstrate the improved damping for the nanocomposite beam, the frequency responses of the regular composite beam and the nanocomposite beam are compared in Figure 6, which clearly shows that the peak magnitude of the first three modes has dropped dramatically. This means that the damping ratio values of the nanocomposite beam at these three natural frequencies are much larger than those of the regular composite beam.

To estimate the damping ratio for each mode, the halfpower bandwidth method was used. Corresponding to each natural frequency, there is a peak in the magnitudefrequency plot of the system. $3 \mathrm{~dB}$ down from the peak, there are two points corresponding to half-power point. A larger frequency range between these two points means a larger damping ratio value. The damping ratio is calculated by using the following equation:

$$
2 \zeta=\frac{\omega_{2}-\omega_{1}}{\omega_{n}},
$$

where $\omega_{1}, \omega_{1}$ are the frequencies corresponding to the halfpower point, $\omega_{n}$ is the natural frequency corresponding to the peak value, and $\zeta$ is the damping ratio. Table 1 shows the first three modal frequencies and associated damping ratio of the two beams. From the damping ratio comparison, it is 


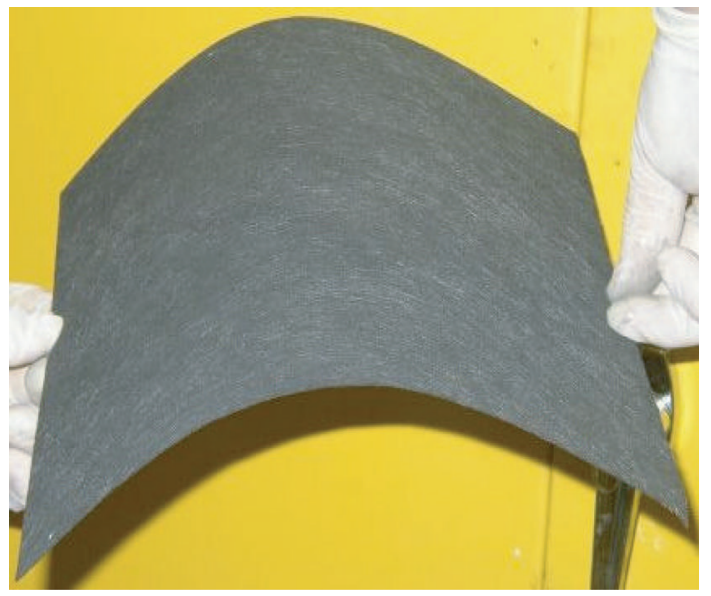

(a)

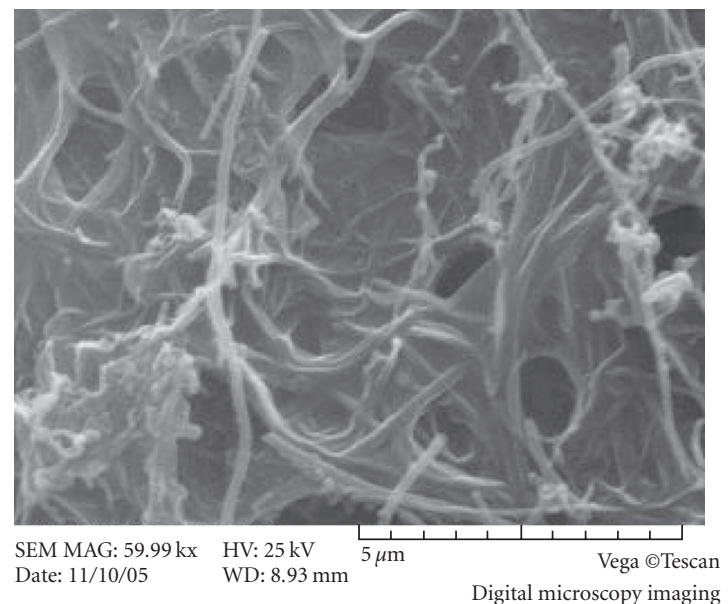

(c)

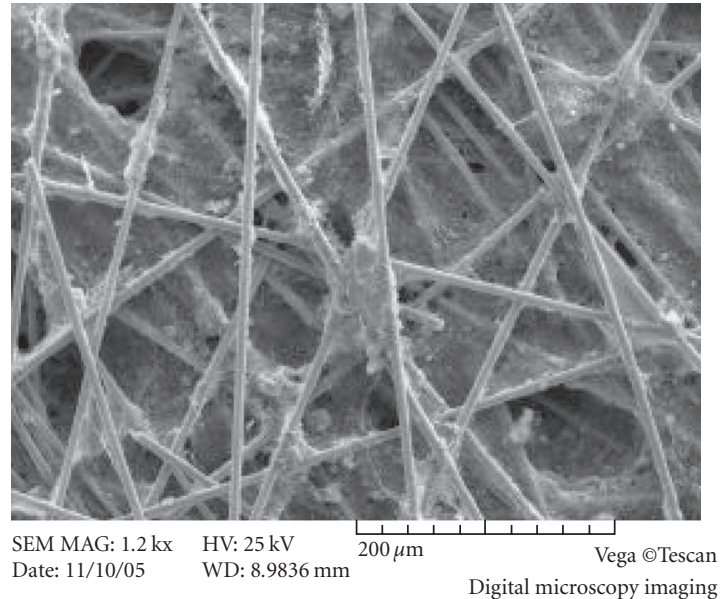

(b)

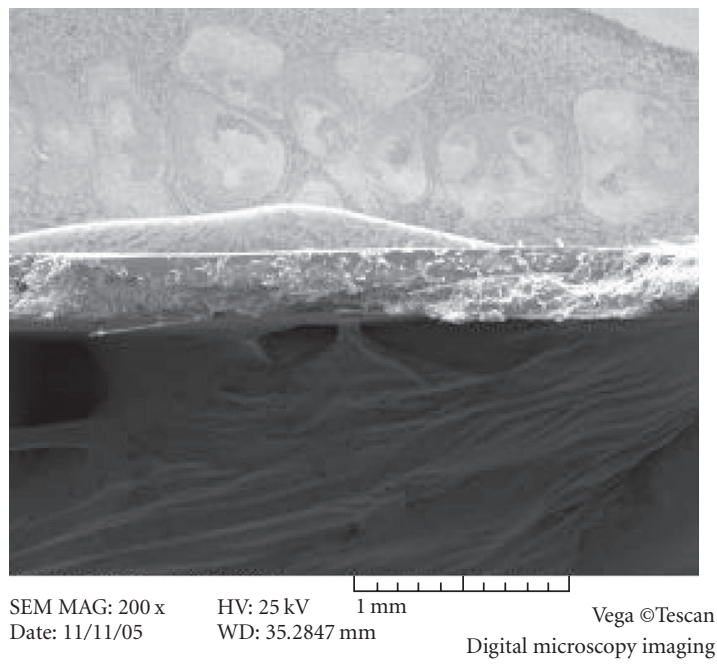

(d)

FIGURE 3: Carbon nanofiber paper and nanocomposites: (a) carbon nanofiber paper in the dimension of a structural element, (b) the porous structure formed by short glass fiber within the paper, (c) the porous structure formed by carbon nanofibers within the paper, and (d) the fracture surface of the nanocomposites.

clear that the damping ratio of the nanocomposite beam has increased up to $200-700 \%$ at the 2 nd mode and 3rd mode frequencies. However, there is little change in mode frequencies, which means that there is slight change in the stiffness of the composites. This demonstrates an advantage of nanocomposite over regular composite with viscoelastic layers. The regular composites with viscoelastic layers will sacrifice in reduced stiffness, though damping is improved.

For the nanocomposite beam with carbon nanofiber paper as surface layer, the analysis shows good agreement with the test data for the nanocomposite beam with carbon nanofiber paper as midlayer, as shown in Figure 7. Therefore, it is concluded that the incorporation of carbon nanofiber paper could result in a significant increase in structural damping of conventional fiber reinforced composites.

\subsection{Tensile properties of carbon nanofiber paper-enabled nanocomposites}

As stated earlier, the tensile properties of the composite laminates with and without carbon nanofiber paper were investigated. Table 2 shows the results from the tensile tests performed on the two sets of tensile specimens. It can be seen that the incorporation of carbon nanofiber paper had slight effects on the modulus and the strength of the composite laminates. 


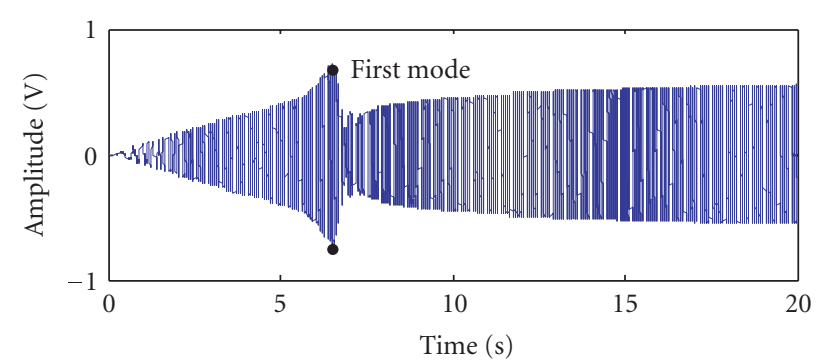

- Regular composite

(a)

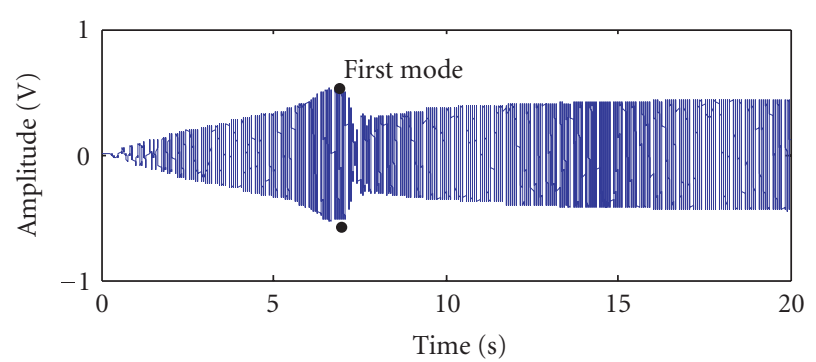

— Nanocomposite

(b)

FIGURE 4: Sweep sine response $(0.1 \mathrm{~Hz}$ to $100 \mathrm{~Hz})$ of the composite beam without carbon nanofiber paper and the nanocomposite beam with carbon nanofiber paper as midlayer.

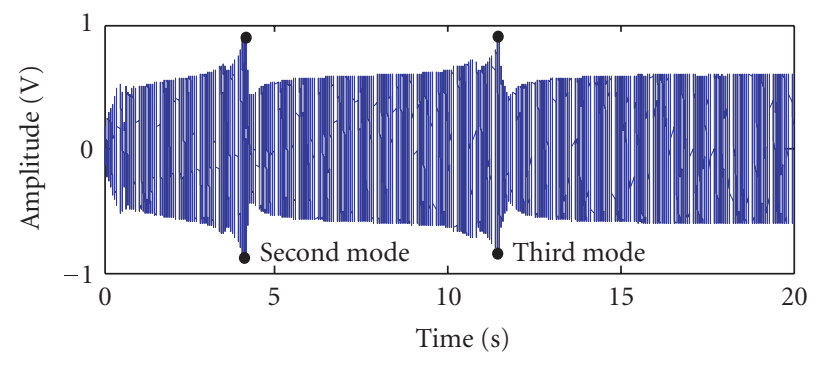

— Regular composite

(a)

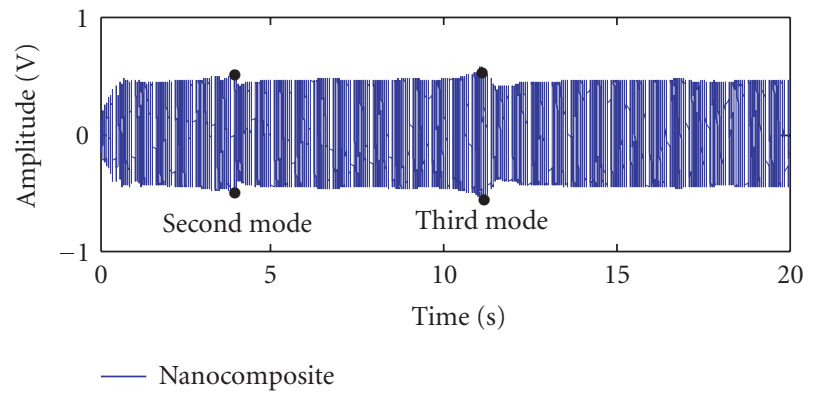

(b)

FIGURE 5: Sweep sine response (10 to $1000 \mathrm{~Hz}$ ) of the composite beam without carbon nanofiber paper and the nanocomposite beam with carbon nanofiber paper as midlayer.

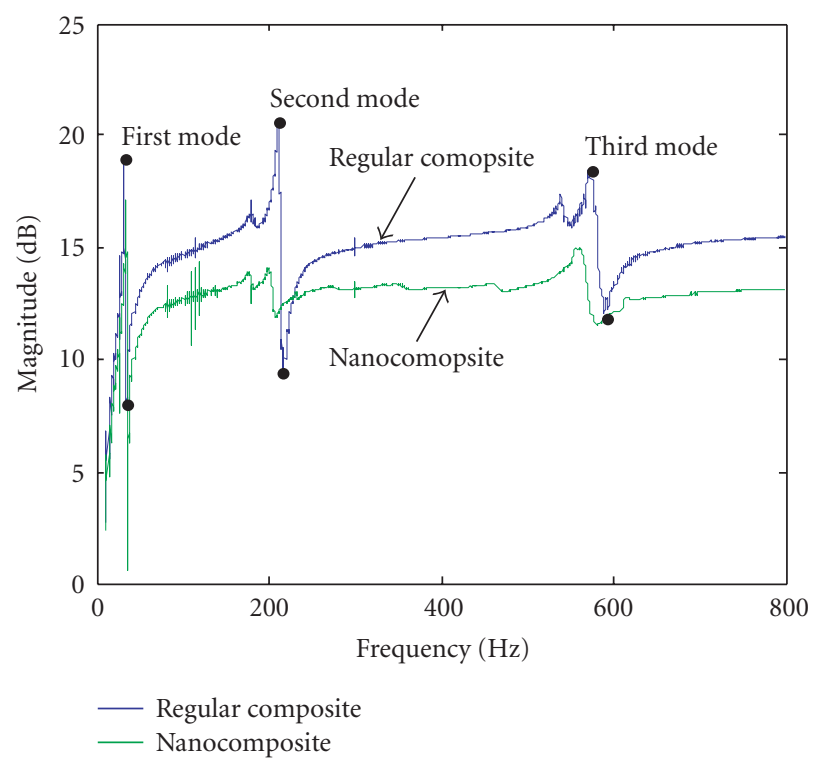

FIGURE 6: Frequency response of the first three modes for the composite beam without carbon nanofiber paper and the nanocomposite beam with carbon nanofiber paper as midlayer.

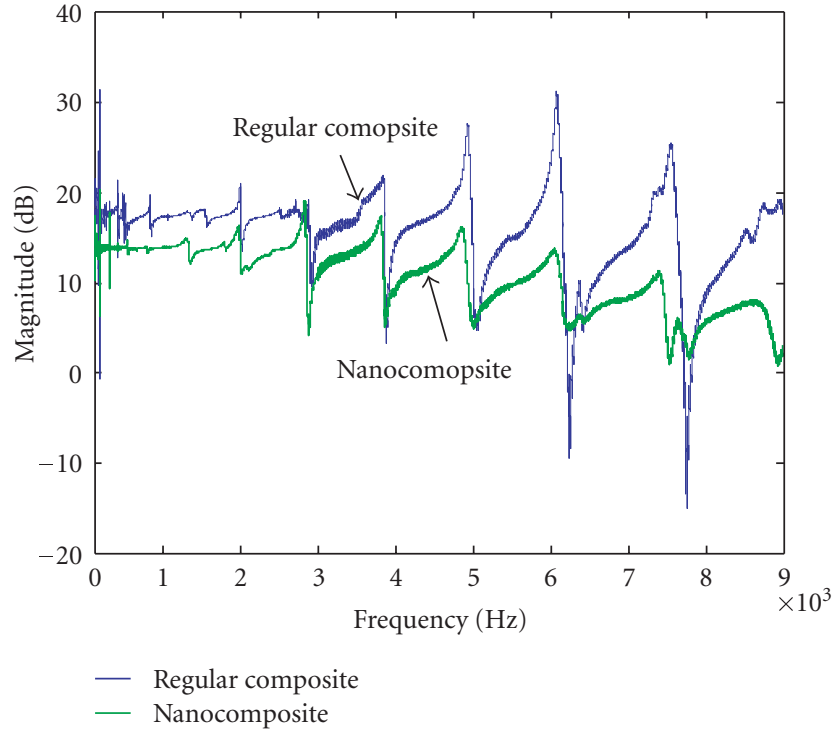

Figure 7: Frequency response of the first three modes for the composite beam without carbon nanofiber paper and the nanocomposite beam with carbon nanofiber paper as surface layer. 
TABLE 1: Damping ratio calculated by half-power bandwidth method.

\begin{tabular}{lcccccc}
\hline & $\begin{array}{c}\text { 1st mode } \\
\text { frequency } \\
(\mathrm{Hz})\end{array}$ & $\begin{array}{c}\text { 1st mode } \\
\text { damping } \\
\text { ratio }\end{array}$ & $\begin{array}{c}\text { 2nd mode } \\
\text { frequency } \\
(\mathrm{Hz})\end{array}$ & $\begin{array}{c}\text { 2nd mode } \\
\text { damping } \\
\text { ratio }\end{array}$ & $\begin{array}{c}\text { 3rd mode } \\
\text { frequency } \\
(\mathrm{Hz})\end{array}$ & $\begin{array}{c}\text { 3rd mode } \\
\text { damping } \\
\text { ratio }\end{array}$ \\
\hline Regular composite beam & 31.93 & 0.0278 & 210.8 & 0.0251 & 572.5 & 0.0349 \\
Nanocomposite beam & 34.60 & 0.0373 & 198.5 & 0.1985 & 558 & 0.1104 \\
\hline
\end{tabular}

TABLE 2: Results from the tensile tests performed on the laminates with/without carbon nanofiber paper.

\begin{tabular}{ll|cccc}
\hline \multicolumn{1}{c|}{ Test specimens } & $\begin{array}{c}\text { Average } \\
\text { thickness } \\
\text { (inch) }\end{array}$ & $\begin{array}{c}\text { Average } \\
\text { width } \\
\text { (inch) }\end{array}$ & $\begin{array}{c}\text { Average } \\
\text { length } \\
\text { (inch) }\end{array}$ & $\begin{array}{c}\text { Tensile } \\
\text { modulus } \\
(\mathrm{ksi})\end{array}$ & $\begin{array}{c}\text { Tensile } \\
\text { strength } \\
(\mathrm{ksi})\end{array}$ \\
\hline 1 & Laminates without carbon nanofiber paper & 0.10 & 0.75 & 5.75 & 1,220 \\
2 & Laminates with carbon nanofiber paper as midlayer & 0.15 & 0.96 & 5.75 & 1,120 \\
3 & Laminates with carbon nanofiber paper as surface layer & 0.10 & 0.75 & 6.25 & 1,300 \\
\hline
\end{tabular}

\section{CONCLUSIONS}

This paper presented the damping tests conducted using the nanocomposite beams with an embedded carbon nanofiber paper as interlayer or surface layer. The composite laminates without carbon nanofiber paper were also tested. The tests indicated up to $200-700 \%$ increase of the damping ratios at higher frequencies and slight change in tensile strength and Young's modulus of composite laminates due to the incorporation of carbon nanofiber paper. The SEM characterization of the carbon nanofiber paper and the nanocomposites showed the entanglement of carbon nanofibers and short glass fibers within the carbon nanofiber paper and the complete penetration of the resin through the carbon nanofiber paper. These cross-linkages within the carbon nanofiber paper are expected to be responsible for the energy dissipation in the nanocomposites due to the strong bonding and nonbonding interactions between carbon nanofibers and short glass fibers.

\section{ACKNOWLEDGMENTS}

The authors would like to acknowledge the financial support provided by the University of South Alabama Research Council (USARC Grant no. 3-61619) and National Science Foundation (CAREER Grant no. 0093737). The assistance by Dr. Kendall Clarke and Mr. Steven Sumerlin is gratefully acknowledged.

\section{REFERENCES}

[1] O. Breuer and U. Sundararaj, "Big returns from small fibers: a review of polymer/carbon nanotube composites," Polymer Composites, vol. 25, no. 6, pp. 630-645, 2004.

[2] E. T. Thostenson, Z. Ren, and T.-W. Chou, "Advances in the science and technology of carbon nanotubes and their composites: a review," Composites Science and Technology, vol. 61, no. 13, pp. 1899-1912, 2001.
[3] K.-T. Lau and D. Hui, "The revolutionary creation of new advanced materials_carbon nanotube composites," Composites Part B: Engineering, vol. 33, no. 4, pp. 263-277, 2002.

[4] F. H. Gojny, M. H. G. Wichmann, B. Fiedler, W. Bauhofer, and K. Schulte, "Influence of nano-modification on the mechanical and electrical properties of conventional fibre-reinforced composites," Composites Part A: Applied Science and Manufacturing, vol. 36, no. 11, pp. 1525-1535, 2005.

[5] F. H. Gojny, M. H. G. Wichmann, U. Köpke, B. Fiedler, and K. Schulte, "Carbon nanotube-reinforced epoxy-composites: enhanced stiffness and fracture toughness at low nanotube content," Composites Science and Technology, vol. 64, no. 15, pp. 2363-2371, 2004.

[6] D. Qian, E. C. Dickey, R. Andrews, and T. Rantell, "Load transfer and deformation mechanisms in carbon nanotubepolystyrene composites," Applied Physics Letters, vol. 76, no. 20 , pp. 2868-2870, 2000.

[7] L. S. Schadler, S. C. Giannaris, and P. M. Ajayan, "Load transfer in carbon nanotube epoxy composites," Applied Physics Letters, vol. 73, no. 26, pp. 3842-3844, 1998.

[8] H. Ma, J. Zeng, M. L. Realff, S. Kumar, and D. A. Schiraldi, "Processing, structure, and properties of fibers from polyester/carbon nanofiber composites," Composites Science and Technology, vol. 63, no. 11, pp. 1617-1628, 2003.

[9] C. Bower, R. Rosen, L. Jin, J. Han, and O. Zhou, "Deformation of carbon nanotubes in nanotube-polymer composites," Applied Physics Letters, vol. 74, no. 22, pp. 3317-3319, 1999.

[10] Z. Ounaies, C. Park, K. E. Wise, E. J. Siochi, and J. S. Harrison, "Electrical properties of single wall carbon nanotube reinforced polyimide composites," Composites Science and Technology, vol. 63, no. 11, pp. 1637-1646, 2003.

[11] J. Sandler, M. S. P. Shaffer, T. Prasse, W. Bauhofer, K. Schulte, and A. H. Windle, "Development of a dispersion process for carbon nanotubes in an epoxy matrix and the resulting electrical properties," Polymer, vol. 40, no. 21, pp. 5967-5971, 1999.

[12] S. J. Park, S. T. Lim, M. S. Cho, H. M. Kim, J. Joo, and H. J. Choi, "Electrical properties of multi-walled carbon nanotube/poly(methyl methacrylate) nanocomposite," Current Applied Physics, vol. 5, no. 4, pp. 302-304, 2005. 
[13] T. Kashiwagi, E. Grulke, J. Hilding, et al., "Thermal and flammability properties of polypropylene/carbon nanotube nanocomposites," Polymer, vol. 45, no. 12, pp. 4227-4239, 2004.

[14] S. Peeterbroeck, M. Alexandre, J. B. Nagy, et al., "Polymerlayered silicate-carbon nanotube nanocomposites: unique nanofiller synergistic effect," Composites Science and Technology, vol. 64, no. 15, pp. 2317-2323, 2004.

[15] W. H. Liao and K. W. Wang, "On the analysis of viscoelastic materials for active constrained layer damping treatments," Journal of Sound and Vibration, vol. 207, no. 3, pp. 319-334, 1997.

[16] H. Kishi, M. Kuwata, S. Matsuda, T. Asami, and A. Murakami, "Damping properties of thermoplastic-elastomer interleaved carbon fiber-reinforced epoxy composites," Composites Science and Technology, vol. 64, no. 16, pp. 2517-2523, 2004.

[17] W. Pulliam, D. Lee, G. Carman, and G. McKnight, "Thinlayer magnetostrictive composite films for turbomachinery fan blade damping," in Smart Structures and Materials 2003: Industrial and Commercial Applications of Smart Structures Technologies, vol. 5054 of Proceedings of SPIE - The International Society for Optical Engineering, pp. 360-371, San Diego, Calif, USA, March 2003.

[18] J. Suhr, N. A. Koratkar, P. Keblinski, and P. Ajayan, "Viscoelasticity in carbon nanotube composites," Nature Materials, vol. 4, no. 2, pp. 134-137, 2005.

[19] N. A. Koratkar, B. Wei, and P. M. Ajayan, "Multifunctional structural reinforcement featuring carbon nanotube films," Composites Science and Technology, vol. 63, no. 11, pp. 15251531, 2003.

[20] N. A. Koratkar, B. Wei, and P. M. Ajayan, "Carbon nanotube films for damping applications," Advanced Materials, vol. 14, no. 13-14, pp. 997-1000, 2002.

[21] J. Gou, B. Minaie, B. Wang, Z. Liang, and C. Zhang, "Computational and experimental study of interfacial bonding of single-walled nanotube reinforced composites," Computational Materials Science, vol. 31, no. 3-4, pp. 225-236, 2004.

[22] Z. Wang, Z. Liang, B. Wang, C. Zhang, and L. Kramer, "Processing and property investigation of single-walled carbon nanotube (SWNT) buckypaper/epoxy resin matrix nanocomposites," Composites Part A: Applied Science and Manufacturing, vol. 35, no. 10, pp. 1225-1232, 2004.

[23] J. Gou, Z. Liang, and B. Wang, "Experimental design and optimization of dispersion process for single-walled carbon nanotube bucky paper," International Journal of Nanoscience, vol. 3, no. 3, pp. 293-307, 2004. 

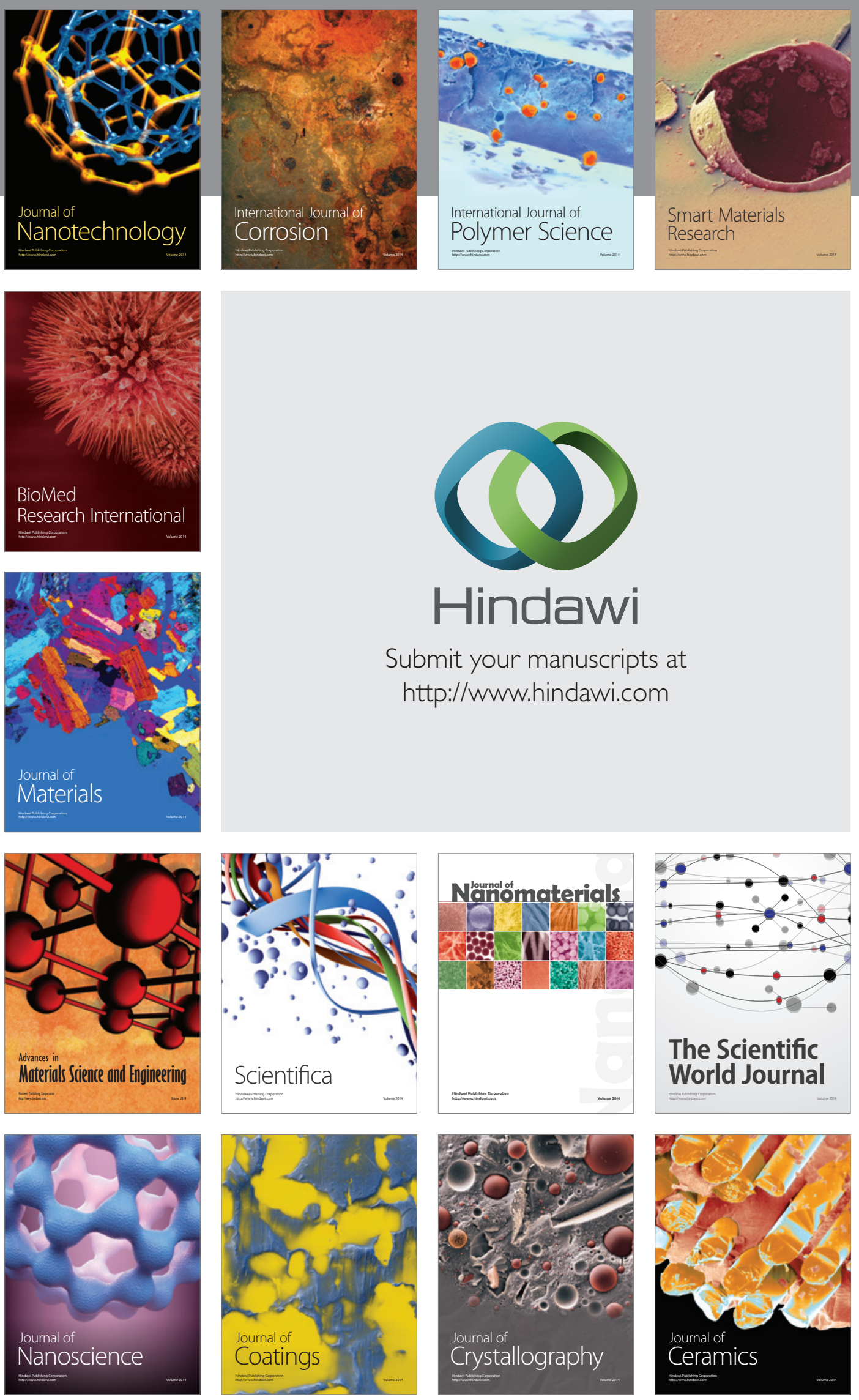

The Scientific World Journal

Submit your manuscripts at

http://www.hindawi.com

\section{World Journal}

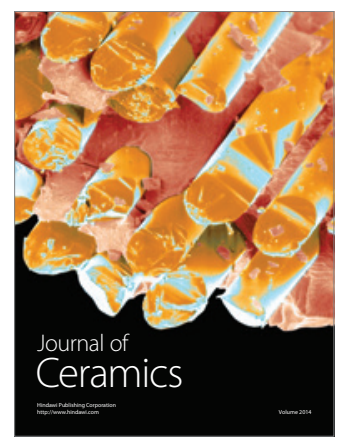

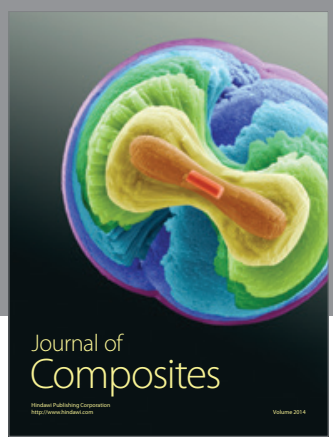
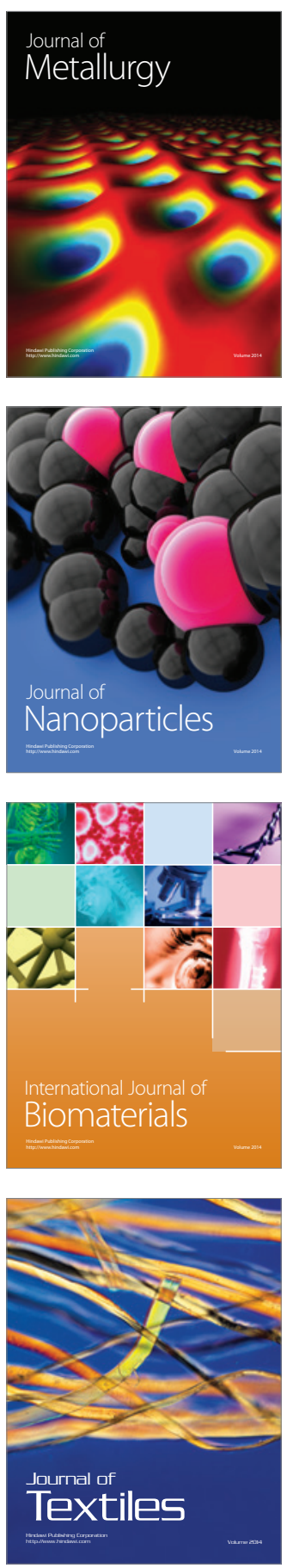